\title{
WEAR ANALYSIS OF DIE INSERTS IN THE HOT FORGING PROCESS OF A FORKED TYPE FORGING USING REVERSE SCANNING TECHNIQUES
}

\author{
Łukasz Dworzak', Marek Hawryluk ', Jacek Ziemba' \\ 1 Wrocław University of Science and Technology, Faculty of Mechanical Engineering, Department of Plastic \\ Forming and Metrology, ul. Łukasiewicza 5, 50-371, e-mail: jacek.ziemba@pwr.edu.pl
}

Received: 2017.09.15 Accepted: 2017.11.01 Published: 2017.12.05

\begin{abstract}
This article presents a wear analysis of die inserts used in the hot forging process of a forked forging (yoke), an element applied in steering systems of passenger vehicles. Studies involved the application of an original reverse scanning method intended for rapid and reliable wear analysis of forging tools (with complicated shape) affording easy assessment without the need to dismount tools from the forging unit. The developed method involves analysis of progressive wear of forging tools based on measurements (scanning) of forgings periodically collected from the process and constitutes a useful tool for measurement and testing. As the authors' earlier works have demonstrated, the proposed new approach to analysis of tool wear with the application of reverse 3D scanning has proven successful in multiple instances in the case of axially symmetrical objects. The presented results of studies indicate that it is possible to utilize the expanded method to analyze the lifetime of forging tools, including tools with complex geometry. Application of the reverse scanning method allows for continuous and practical monitoring of the condition of forging tools over the course of the forging process and should have a positive impact on improving production output and reducing production costs.
\end{abstract}

Keywords: forging tool wear, destructive mechanisms, reverse 3D scanning, lubricating and cooling device

\section{INTRODUCTION}

Forging die inserts used in industrial hot forging processes are characterized by a relatively low lifetime, which has a direct effect on the quality and cost of manufacturing forgings. Mutual, quantitative proportions of individual destructive mechanisms affecting forging tools vary greatly and mainly depend on the operational conditions present during the forging process. To a lesser extent, a tool's resistance to destructive mechanisms depends on its design (shape of the working surface), the tool material and its proper heat treatment, as well as treatment of the surface layer, while the shape of the forging preform has the least influence $[9,27,28,32]$. In the literature, lifetime is usually defined, from a produc- tion perspective, as the number of forgings that meet qualitative requirements manufactured by means of the given tool. However, from a scientific point of view, tool lifetime is linked to its resistance to destructive factors occurring during work. In this case, objective assessment and analysis of destructive mechanisms causing wear or destruction of the tool is of great significance, as opposed to the case of the definition from the production-based perspective, where emphasis is placed on the operator's subjective assessment [15]. Loading of dies and punches is periodically variable in nature and constitutes a combination of thermal and mechanical load, which results from contact between the hot preform material and the relatively cold tool. Variable thermal load has a significant impact on die lifetime, as it is the 
main cause of cracks and changes of physicomechanical properties of the tool's surface layer, in addition to its exponentiation of abrasive wear, which is initiated, above all, by high mechanical pressing forces. The primary and most common destructive mechanisms include: abrasive fatigue, mechanical cracking, plastic deformation as well as thermal and thermomechanical fatigue [1-3, $5,14,22,25-26,30,33-34]$. Analysis of wear and lifetime is an exceptionally difficult task. The multitude of factors affecting the correctness of the forging process, and thus tool lifetime, has spurred the application of a series of CAD/CAM/ CAE and FEM tools for analysis and optimization of forging technologies, including for the purposes of extending lifetime $[15,26,35]$. Currently, an increasing number of scientific research centers, whether at universities, R\&D units or industrial plants, are employing a comprehensive approach to lifetime assessment of forging apparatus. The influence of individual factors on tool lifetime is generally analyzed separately, and it is difficult to find a global description of a destructive process that would account for all factors and phenomena simultaneously, so employing a systematized and comprehensive approach allows for a broader picture and more complete lifetime analysis. Such a comprehensive approach involves conducting a large number of different tests, including: analysis of forging technology (force measurement, thermovisual tests), macroscopic observations and tests, combined with scanning of tool impressions, microhardness measurements, advanced metallographic microscopy, numerical modeling, as well as the utilization of specialized laboratory standard dedicated for analysis of specific destructive mechanisms and modern systems for measurement and analysis, statistical operational analysis and the application of expert systems. Unfortunately, such tests are time-consuming and often very costly. This is why methods that are quick, practical and make it possible to obtain the most important information in the context of wear are sought after or chosen $[10,15-16,23,25-26,35]$.

Currently, due to the production costs of forging tools resulting from the complicated shape of forged products, growing interest of the industry in studies related to improvement of forging tools' lifetime can be observed. Interest in applying measurement and analysis of tools' wear progression by means of contactless measurement techniques is noticeable, e.g. using measuring arms with in- tegrated laser and 3D scanners [11,16-19,18-20, $24,29,36]$. Methods based on the scanning technique employing mobile measuring arms with an integrated scanner are very practical, as they afford high mobility and make it possible to move the measuring stand from one location to another in a production plant, directly to the tested object (e.g. from a laboratory to a forging unit), for the purpose of rapid measurement and analysis of results, e.g.: heavy die, steel plate, etc., without the need to dismount tools and interrupt production in order to assess critical geometric features $[11-12,18]$. Thanks to their mobility and universality, measuring arms are also an alternative to coordinate measuring machines in applications permitting lower accuracy of measurement [21, 31]. Publications concerning the application of scanning measuring techniques can be found in the available literature, mainly for final quality control of products [24, 29,], but increasingly often, also for control of forging tools and instrumentation [11-13, 18]. It should be noted that the application of scanning techniques only allows for determination of geometric changes relative to the assumed nominal object, i.e. measurement of material loss in the normal direction or changes in volume. It should also be emphasized that measurement of selected geometric features conducted during standard quality control of die inserts at the end of their work cycle does not provide an answer concerning a specific destructive mechanism. In very few cases, obtained results may indicate the size of abrasive wear on forging tools. As demonstrated by many years of studies concerning analysis of the surface layer of forging tools by the authors of this paper, in the case of forging processes at elevated temperatures and under typical tool working conditions (lubrication and cooling), the percentage share of abrasive wear as the dominant destructive mechanism decreases while the share of thermomechanical fatigue significantly increases, accelerating visible and easily measurable abrasive wear, as a result of which tools are withdrawn from production. A slightly different situation takes place in the case of forging tools that are not lubricated and cooled, for which the typical destructive mechanism is abrasive wear and plastic deformations $[8,15$, 25]. This is why it is justified and significant to conduct tests, particularly with the application of scanning techniques, for the purpose of rapid assessment of actual wear and the current condition of forging tools over the course of their operation 
without the need to interrupt production or dismount tools from the forging unit. Interpretation of the results of such tests and analyses may help to find ways of optimizing performed die forging processes [9, 15-16].

This paper presents the results of studies concerning wear analysis of die inserts used in preliminary die forging of a forked forging via the application of scanning techniques and an original reverse 3D scanning method developed by the authors.

\section{ANALYSIS OF THE PROBLEM STATE}

Die forging processes are among the most difficult manufacturing processes to perform. Despite the fact that this technology is relatively well understood, proper manufacturing of forgings with complicated shapes that would meet accuracy and quality requirements posed by recipients requires much experience from process engineers and operators.

\section{Study of contactless measurement applications for forgings and forging instrumentation}

At every stage of the technological forging process, there is a potential risk of error causing a drop in the quality of manufactured forgings. The basic factors affecting the quality as well as the dimensional and shape accuracy of forgings include: tools (mainly the quality of their manufacture) as well as machinery and equipment (working condition, clearances, etc.) used in die forging processes. Wearing of forging tools and other instrumentation (housings, compensating rings, sleeves, base plates, wedges, etc.) causes a change in the geometry of the manufactured product, and any surface defects of the tool (cracks, losses) are reflected on the forged product, affecting the quality of the ready product. A similar situation occurs in the case of forging units and other auxiliary equipment. Presses and stamps working under the difficult conditions present during forging are frequently over-exploited, which results in significantly more rapid wear of elements and subassemblies $[4,6,8,37]$. This is why detailed quality control of not only the forging but also forging instrumentation is very important during production. Classical measuring methods that are currently applied do not allow for rapid and comprehensive assessment of the quality and accuracy of the entire object. Such analyses are possible thanks to the application of coordinate measuring techniques (CMT) and now increasingly frequently thanks to the utilization of contactless methods and measuring devices, i.e. scanners or measuring arms with integrated scanners, which allow for measurement directly during production. Continuous improvement of measuring accuracy can be observed in industrial optical scanners and linear laser scanners, which, along with their mobility, significantly increases their competitiveness in comparison to classical coordinate measuring machines in applications requiring less accuracy $[7,21,31]$. This is related to the increasingly frequent application of blue rather than red light sources, which has a significant impact on measuring accuracy, and which, in the case of optical scanners, allows for partial elimination of the need to make details matte (tarnishing).

Applications of 3D scanning measuring techniques in the forging industry are mainly employed for two groups of objects: forgings and forging tools, and decidedly less frequently employed for assessment of the condition of tools used to manufacture a given product or similar applications [11- 13, 19, 24, 29, 36]. Measurements utilizing measuring arms equipped with integrated linear scanners are being applied successfully with increasing frequency in the process of forging quality control. Fig. 1a presents a cover plate forging prepared for measurement, and Fig. 2a shows a lead forging of a car piston prepared for scanning. Fig. $1 b$ and Fig. $2 b$ show the results of shape error measurement of the imaged surface of the cover plate forging and car piston forging.

The same tools and measuring instruments are used for forging instrumentation as for forgings. However, heated tools are measured very rarely. During hot die forging, tools are subjected to very high, periodical thermal loads ranging from 80 to $600^{\circ} \mathrm{C}$ as well as to mechanical loads reaching above $1200 \mathrm{MPa}$.

Fig. 3 presents selected scanning results for die inserts used to forge forked forgings. Fig. 4 presents scanning results for a punch used in the multi-operational forging process of a constantvelocity joint housing (measuring accuracy of applied scanner at $+-0.025 \mathrm{~mm})$. Contactless measuring techniques are used with increasing frequency during tool regeneration through pad welding, which is based on covering worn tool surfaces with an additional layer of filler material 
a)

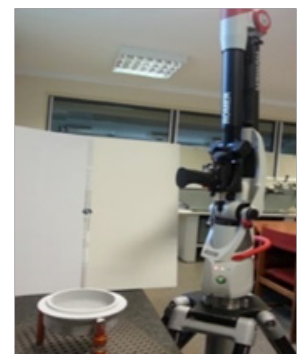

b)

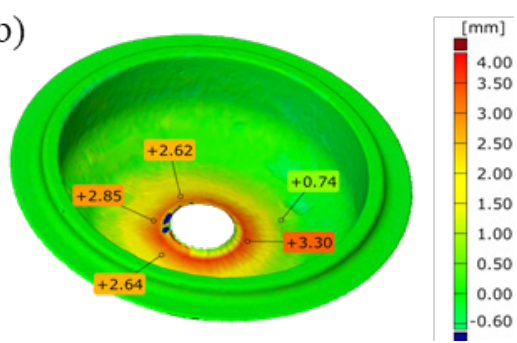

Fig. 1. Measuring stand for laboratory tests of forgings with ROMER Absolute ARM 7520si measuring arm, equipped with integrated laser scanner, b) measured forging [12]

a)

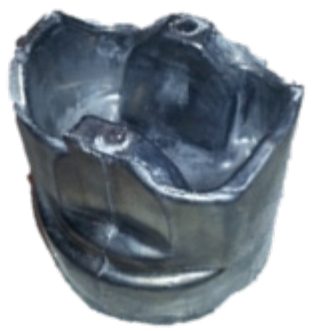

b)

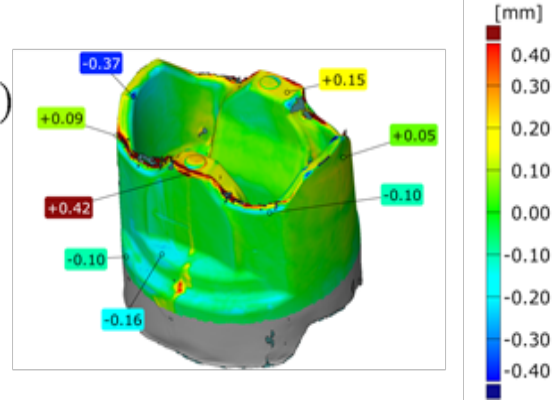

Fig. 2. Scanning of piston forging: a) forging made from $\mathrm{Pb}$ via physical modeling, b) scanning results [18]

a)

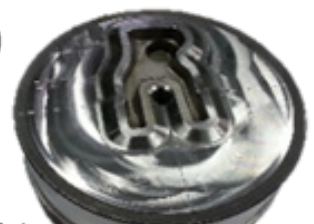

b)

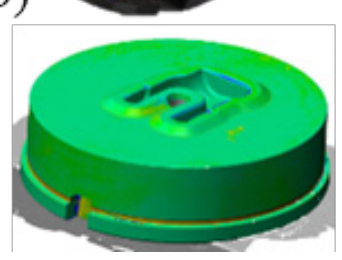

c)

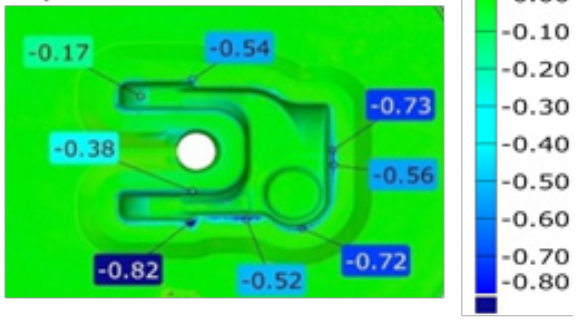

Fig. 3 a) Die insert intended for scanning, b) scanning result - isometric and c) view from the top

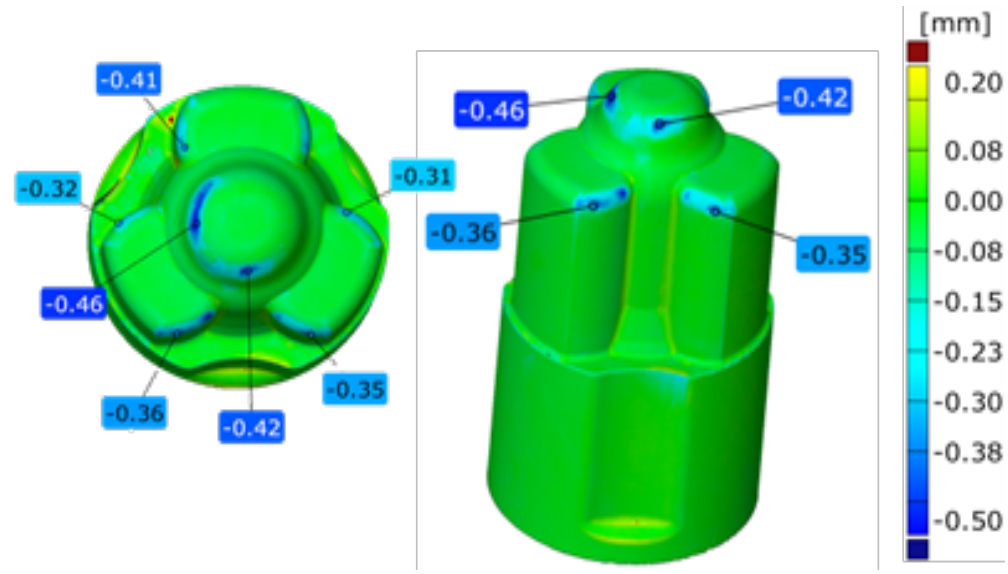

Fig. 4 Punch compared with CAD model after forging of 4120 pieces 
[15]. The authors analyzed the possibility of applying contactless measurements for analysis of tool wear in the trimming and cold hole-punching process. One of the analyzed processes was a set of tools used to trim face wheel forgings (Fig. 5).

The application of a mobile measuring arm equipped with a scanner can be much more advanced and not necessarily implemented in a laboratory but also directly during production, e.g. in continuous assessment of forging tool lifetime. The authors conducted wear measurements of a selected axially symmetrical forging tool (with a simple shape) on the basis of measurements of forgings periodically taken from the process directly during production and additionally verified these measurements on the basis of rapid analysis of the given tool's condition during short technological breaks, without the need to dismount it. Fig. 6 presents a comparison of changes in forging geometry after production of a specific number of pieces and filler consumption (corresponding to the same number of manufactured forgings, at half and at the end of the tool's lifetime).

The presented (Fig. 6) comparison of forging scans and of the tool scans corresponding to them was intended to compare the enlarging areas subjected to wear over the course of operation. By analysis of the volume increase in the case of forgings and loss in the case of the tool, it can be accepted that these volume changes are at a simi-

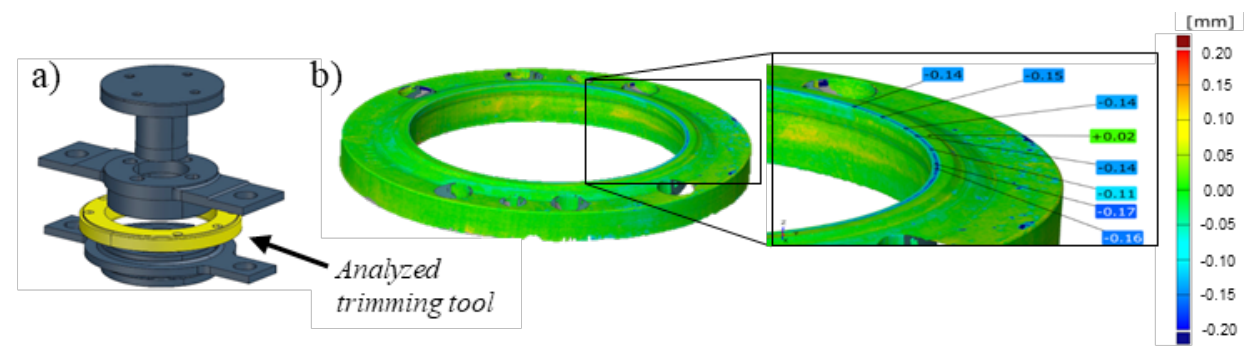

Fig. 5 a) Set of tools for face wheel trimming b) scanning - trimming tool wear analysis [19]

a)

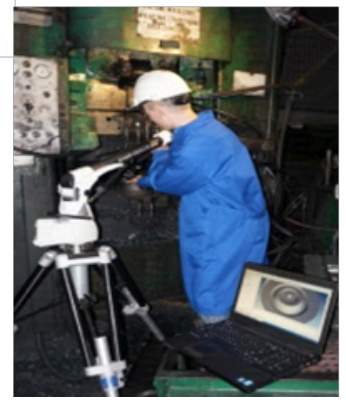

b)

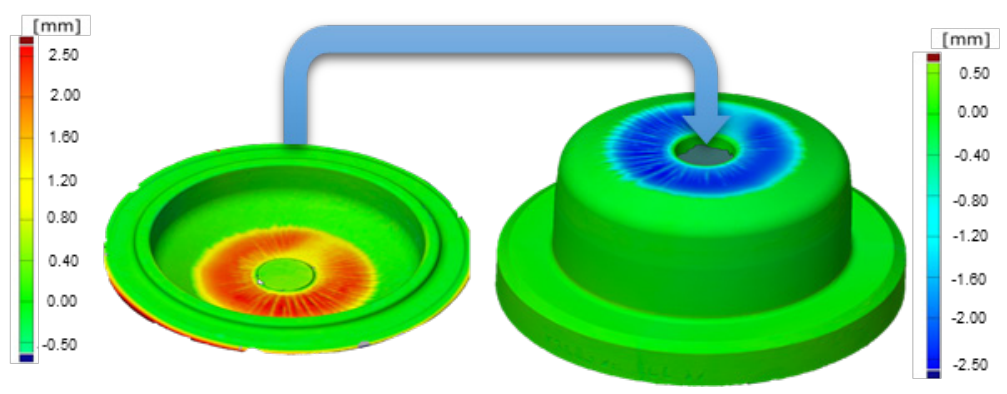

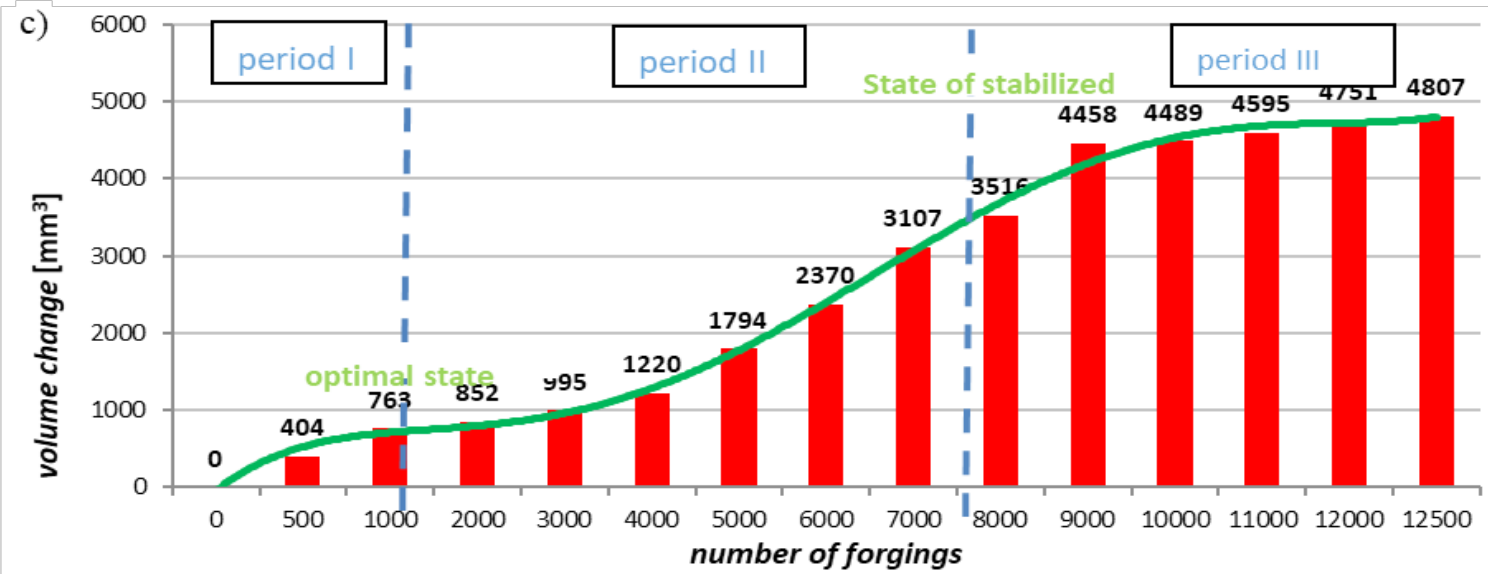

Fig. 6 a) Tool measurement via measuring arm, directly during production, b) comparison of scans of the interior part of forgings and the tools corresponding to them, in the form of quantitative geometric changes of the forging and tool, after 12,500 pieces, c) dependency describing volumetric die wear as a function of the number of forgings manufactured [12] 
lar level. Insignificant differences in obtained results are due to the scanner's measuring accuracy as well as the temperature difference of scanned elements (filler temp. approx. $120-150^{\circ} \mathrm{C}$, ambient temp. for forging).

The interest exhibited by the industry spurs an inclination to analyze scanning techniques with regard to the possibilities of their application and development in the forging industry, including for: analysis of changes in tool geometry during the forging process as well as continuous assessment of forging tools' condition on the basis of forgings with more complicated shapes that are periodically collected and scanned.

\section{RESEARCH METHODOLOGY}

Studies pertain to wear analysis of die inserts applied in the industrial forging process of a forked forging - a yoke, being a critical element (of complicated shape) applied in the steering systems of passenger vehicles, and were based on the application of the developed reverse scanning method for practical assessment of the condition of die inserts. The ROMER Absolute ARM 7520si measuring arm with integrated RS3 scanner along with Polyworks software enabling scanning in Real Time Quality Meshing technology was selected for studies utilizing the contactless measuring method of scanning tools and forgings over the course of the forging process. This machine makes it possible to perform measurements using an RS3 laser scanner integrated with the arm, which provides the capability of collecting up to 460,000 points/s for 4600 points on a line at a linear frequency of $100 \mathrm{~Hz}$ with a declared 2-sigma accuracy of $30 \mu \mathrm{m}$. According to standard B89.4.22, the accuracy of the IS scanning system is $0.053 \mathrm{~mm}$. Tests were conducted in order to analyze the wear progression on the selected tool in two stages. The first stage was tool wear analysis on the basis of direct scanning of tool working surfaces. In the second stage, periodically collected forgings were scanned, and analysis of progressing material increment, simultaneously corresponding to material loss on tools, was conducted on this basis. Next, the curve of forging geometric changes (material increment) was determined and verified with measurements involving direct scanning of tools.

\section{Description of the analyzed process}

The yoke forging process is performed on a Massey press with a nominal pressing force of 13 $\mathrm{MN}$, with a crank radius of $127 \mathrm{~mm}$, crank length $610 \mathrm{~mm}$ and press speed 90 strokes/minute (Fig. 7). All tools are heated to a temperature of approx. $250{ }^{\circ} \mathrm{C}$.

In the analyzed process, die inserts are made from WCL steel. After heat treatment, they are characterized by a hardness of 48-52 HRC. Tools are not nitrided. In order to ensure material deformation that is as uniform as possible throughout its entire volume, preliminary and finishing die forging inserts are lubricated with an aqueous graphite solution with a concentration of 1:20. Forked forgings are an important safety element in a vehicle (as a part of the steering gear) and require special monitoring as well as attention during production, in addition to the development of advanced techniques for their manufacturing and for ensuring their repeatability. In the final product, it is desirable to obtain the required hardness and the proper structure throughout the forging's entire cross-section following heat treatment as well as high strength and fatigue properties. Fig. 8 presents photographs of an example forging, detail and entire component constituting an element of a passenger car's steering gear.

The yoke forging is made from $\mathrm{C} 45$ steel. The yoke's net weight is $0.32 \mathrm{~kg}$. After the rod is cut to the proper dimensions, the stock material is heat-

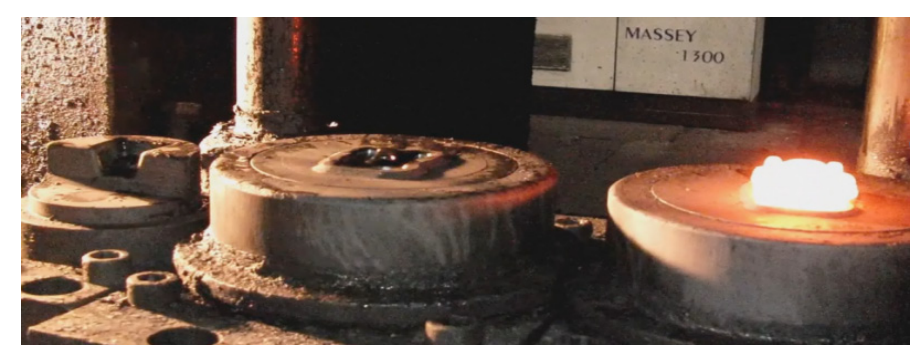

Fig. 7. General view of the yoke forging process - photograph of bottom die inserts with preform placed in the insert's impression prior to finishing forging 
a)

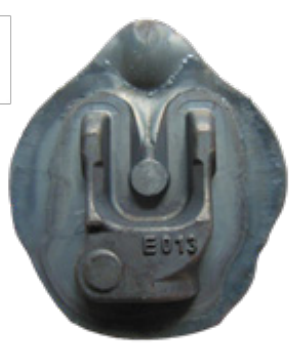

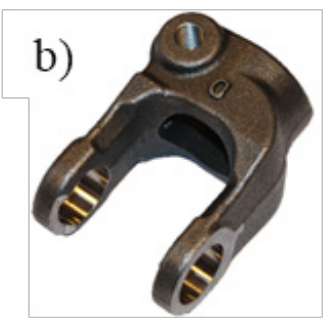

Fig. 8. Photographs: a) yoke forging with flash, b) ready detail - after mechanical processing, c) part of the steering column with yokes

ed to $1120^{\circ}-1150^{\circ} \mathrm{C}$ and then subjected to 3 hot forging operations. In the first forging operation, the stock is upset forged and then flattened. In this first operation, the part of the material intended to be the yoke is flattened, and the unflattened part of the stock will constitute the filler for the rear part of the yoke, which has a larger cross-section. Subsequent preliminary and finishing forging operations are performed in die inserts and endow the material with the shape of the ready product. Next, the cooled forging is trimmed, i.e. the flash is separated from the useful part. Preliminary observations and analysis of the forging process demonstrated that yoke forging is a difficult element to manufacture due to large changes in cross-sections. Low durability is a significant problem due to intensive abrasive wear of preliminary die forging inserts (2nd central forging operation - fig. 8), particularly in the vicinity of the material's flow into the flash groove. Various procedures and methods of improving durability are currently applied to extend these products' lifetime, including: introduction of new tool materials - hot-work steel and optimization of friction conditions - optimization of the lubrication system. Depending on the applied tool material, average lifetimes (determined as the number of manufactured forgings until terminal wear) are: approx. 8,000 forgings for WCL steel, approx. 16,000 forgings for Unimax steel.

\section{RESULTS AND DISCUSSION}

Fig. 9 presents cumulative scanning results for bottom die inserts used in preliminary die forging operations after different numbers of manufactured forgings, made from two different tool materials, and working under different tribological conditions. Prior to scanning, inserts were cleaned from lubricant residue and scale and then measured to generate a point cloud, transformed into a triangular mesh and then compared to the CAD model.

The presented comparison of insert scans (Fig. 9) points to interesting tool wear results. Namely, it can be seen that, in all cases, the application of the new lubricating and cooling device, enabling precise setting of the lubricant dose, reduced tool wear. Work on selecting the optimal output of lubricant and other lubrication settings is still underway, however preliminary results are very satisfactory. It can also be observed that ensuring better tool lubrication conditions resulted in certain shifts in the wear of selected tool areas in the case of WCL inserts (Fig. 9a and 9b).

For example, for the tool presented in Fig. 9b, wear appeared at locations where the forging's "tines" are formed, while there are no wear traces in this area for the tool presented on Fig. 9a (with the old lubricating device). However wear is generally greater in the latter case, mainly occurring in the area where the forging's "shaft" is formed. This provides an inclination to conduct more advanced tests concerning both optimization of the lubricant dose and the direction of its feeding, frequency and additional parameters related to the lubrication process. In turn, in the case of Unimax inserts, the application of the new lubricating devices also reduced wear significantly, however it did not cause shifts in tool areas subjected to wear. Comparing the Unimax tool after 16,000 forgings (Fig. 9d) to the insert made from the same material but with the old lubricating device (Fig. 9e), clear differences in wear to the detriment of the latter can be seen. In turn, a comparison of the type of tool material used for inserts yields the observation that Unimax steel (Fig. 9c) provides greater protection against wear compared to $\mathrm{WCL}$ steel (Fig. 9b). Based on analysis of the presented results, it can be stated that the best solution is to apply Unimax steel as the tool material and the new lubricating device. 


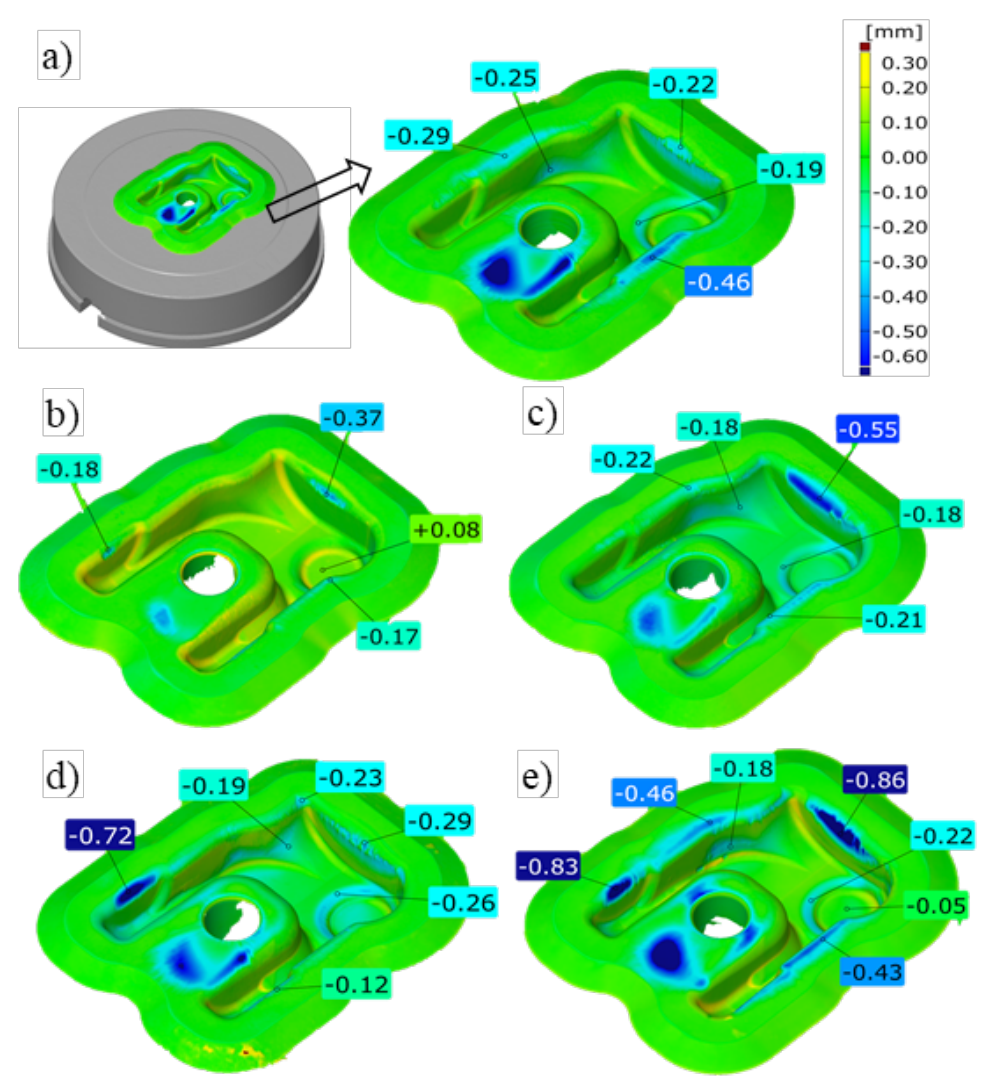

Fig. 9. Scanning results for: a) WCL inserts after 9,000 forgings with old lubrication system, b) WCL inserts after 8,000 forgings with new lubrication system, c) UNIMAX inserts after 8,000 forgings with new lubrication system, d) UNIMAX inserts after 16,000 forgings with new lubrication system, e) UNIMAX inserts after 16,000 forgings with old lubrication system

In order to determine the wear history of one selected die insert (Fig. 9d), the reverse scanning method developed and partially expanded by the authors was applied. This method, which has already proven successful in the case of objects of simple shape, is based on analysis of progressing wear on forging tools on the basis of measurements (scanning) of forgings periodically collected from the process and constitutes a useful tool for measurement and testing. Until now, this method was successfully applied to axially symmetrical objects with relatively simple shapes and high values of material loss. However in the case of a forked forging, such analysis is a significantly more difficult challenge. One of the reasons for this is the non-repeating shape of the forging as well as the fact that it is relatively small in comparison to the measuring accuracy of current scanners, including the RS3 scanner integrated with the ROMER Absolute ARM 7520si measuring arm (accuracy of IS scanning system is $0.053 \mathrm{~mm}$ according to standard B89.4.22). The second significant problem is to adopt the proper reference model and base surface, since improper selection will lead to large dispersion of results. Both of these issues are the main cause of numerous complications in the proper determination of volumetric changes describing the wear phenomena of die inserts. The method developed by the authors [18] is based on measurement via scanner of progressing wear of a selected forging tool (Fig. $10 \mathrm{a})$, expressed in the form of material loss, and on measurement of the shape changes of forgings periodically collected from the process, expressed in the form of material accretion (Fig. 10b).

Selection of base surfaces is of critical significance in the reverse method, and this issue was discussed in works $[12,16,18,20]$. In the presented analysis of the yoke forging (Fig. 11c), it was decided to determine the reference model by employing best-fit equalization for periodically collected forgings in the form of elements selected from the scan image of the 100th forging (Fig.11a). Results of die wear analysis (Fig. $9 \mathrm{~d}$ ) were used in order to determine the shape of reference surfaces, and on this basis, the surfaces of the reference model were defined by selecting only parts of the surface with minimum abrasive 
a)

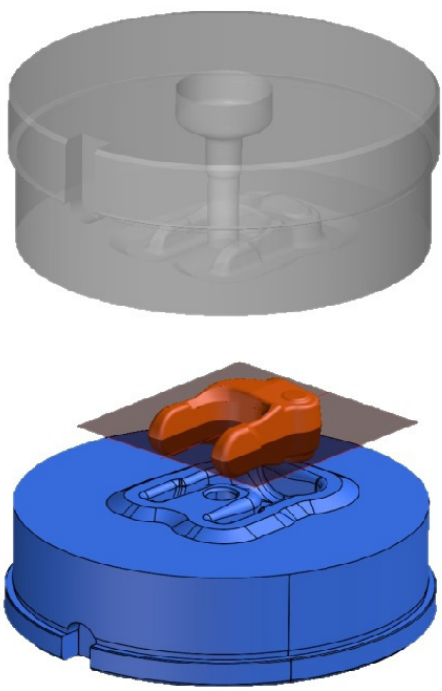

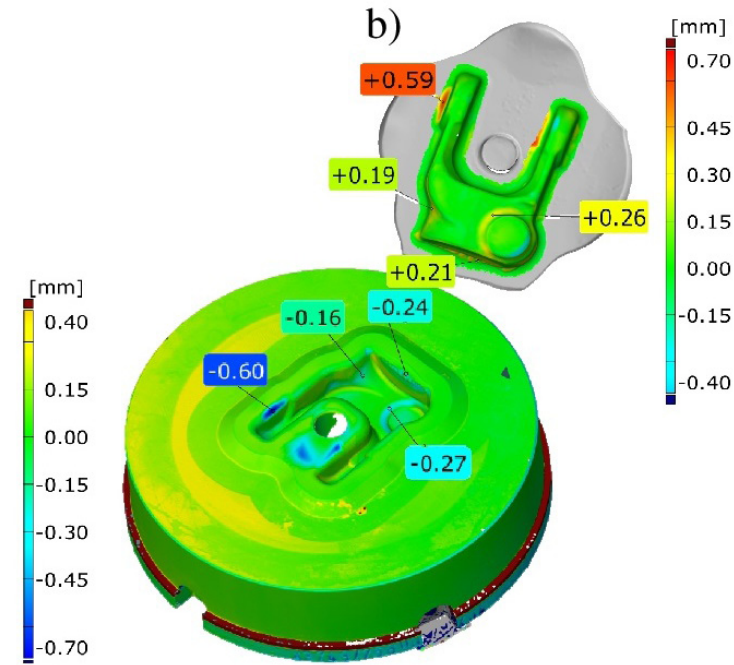

Fig. 10. Concept of the reverse method - reproduction of the wear history of scanned forging tools: a) set of forging tools for the second operation, b) comparison of scans of the final forging and die insert after 16,000 forgings, in the form of shape change of determined surfaces

wear from the scan of the 100th forging (Fig. $11 \mathrm{~b}-$ yellow). It was accepted that the 100th forging represents the geometry of the nominal (new) tool. Next, it was accepted that the scan of the 100th forging constituted the reference model (nominal) for analysis of successive scans of forgings manufactured by the selected bottom die insert (Fig. 9d). The result of the comparison (Fig. 11c) is a coloured map of deviations distributed on the surface of the 16,000th forging's scan image, showing the deviation value of the error of the selected surface from the nominal dimension, which was the scan image of the 100th forging.

In order to reconstruct the wear progression of the die, scanning of forgings selected from the production series (every 1000 pcs.) from a total quantity of 16,000 forgings was performed for the selected die insert (fig. 9d). Fig. 12 presents selected scans of forgings (every 1000 pcs.) in the form of shape change of the defined surface in comparison to the scan of the 100th forging, which were acquired according to the measurement technology described above.

The results indicate that progressing tool wear can be observed for as the number of forgings increases thanks to the employment of the reflection of the tool image on the surfaces of successive forgings and comparing it to the "unworn" 100th forging. Such reconstruction of the progression of wear makes it possible to conduct analysis at an interval equal to the frequency of forging acquisition. The presented results of wear analysis, calculated on the basis of forging analy- sis, are very similar to the results of typical die wear analysis at the end of the forging process.

So it can be assumed that by employing the reflection of tool changes occurring over the course of forging process on periodically collected forgings, obtained results are concurrent and allow for analysis of progressing wear of forging tools, including those of complicated shape.

More in-depth local analysis of results also allows for observation of developing wear on selected tool surfaces. "Blue" areas appearing in the "shaft" part of the forging, which are underfills, can also be observed (Fig. 12e). This may indicate errors made in the forging process, which may result e.g. from improper lubrication. The studies conducted by the authors demonstrated that, in the case of excessively intensive lubrication for inserts of this type, the unevaporated part of the lubricant may accumulate in the lowest part of the tool, making proper filling of the impression impossible. Moreover, after a certain period of time, this may lead to the occurrence of very high pressure, and in consequence, the Rebinder effect, which results in cracking of the tool [15].

Analysis employing measurement of volume changes occurring over the course of the die wear process is an expansion of the method of forging tool wear analysis based on forging measurement. Such an approach allows for a global yet complete description of material loss through observation of volume changes over the course of the forging process. 
a)
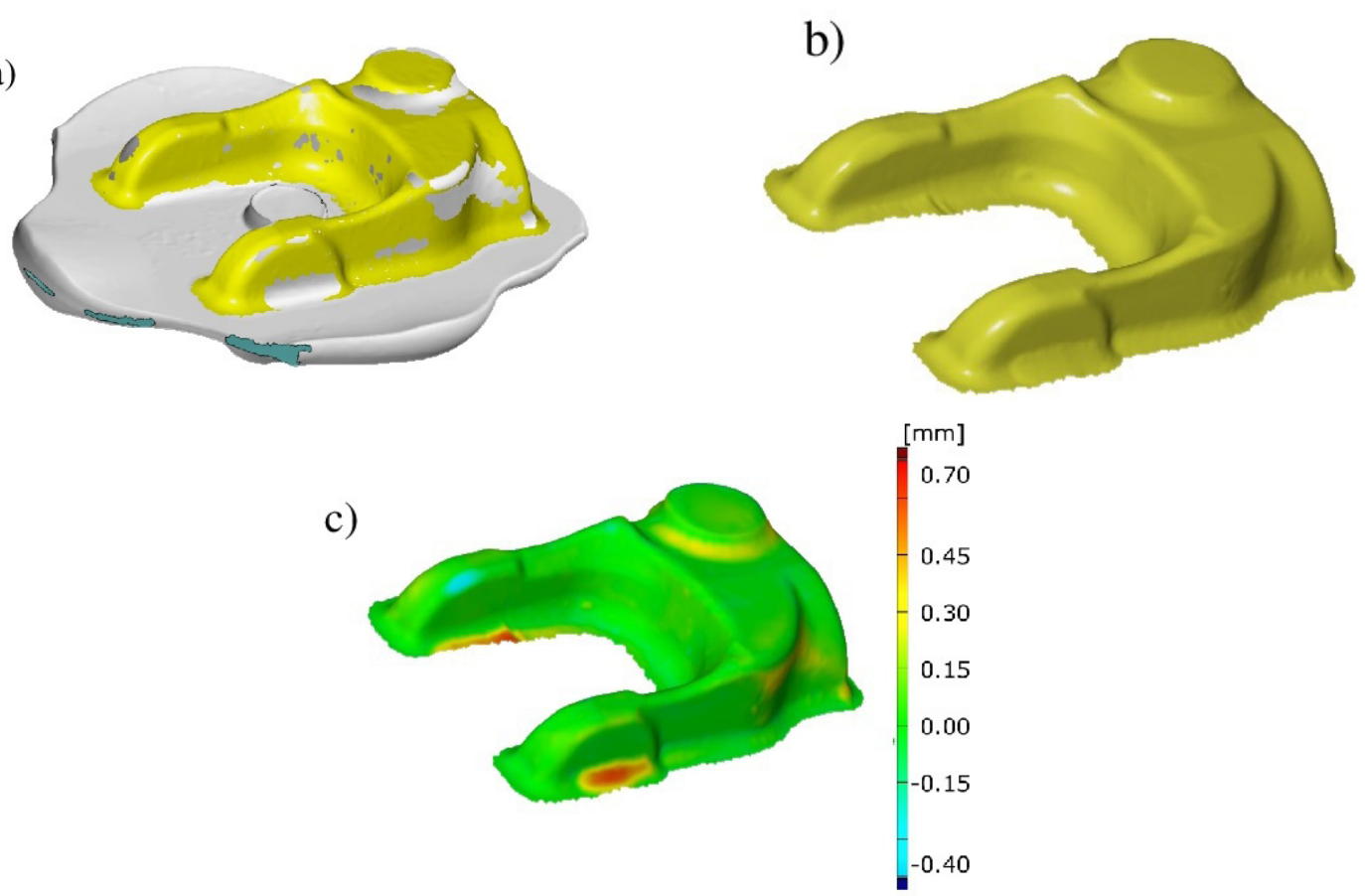

Fig. 11. a) Scan image of the 100th forging and reference for best-fit equalization, for periodically collected forgings in the form of elements selected b) scan image of the 16000 th forging, c) result of comparison of the 16,000 th and the 100th forging

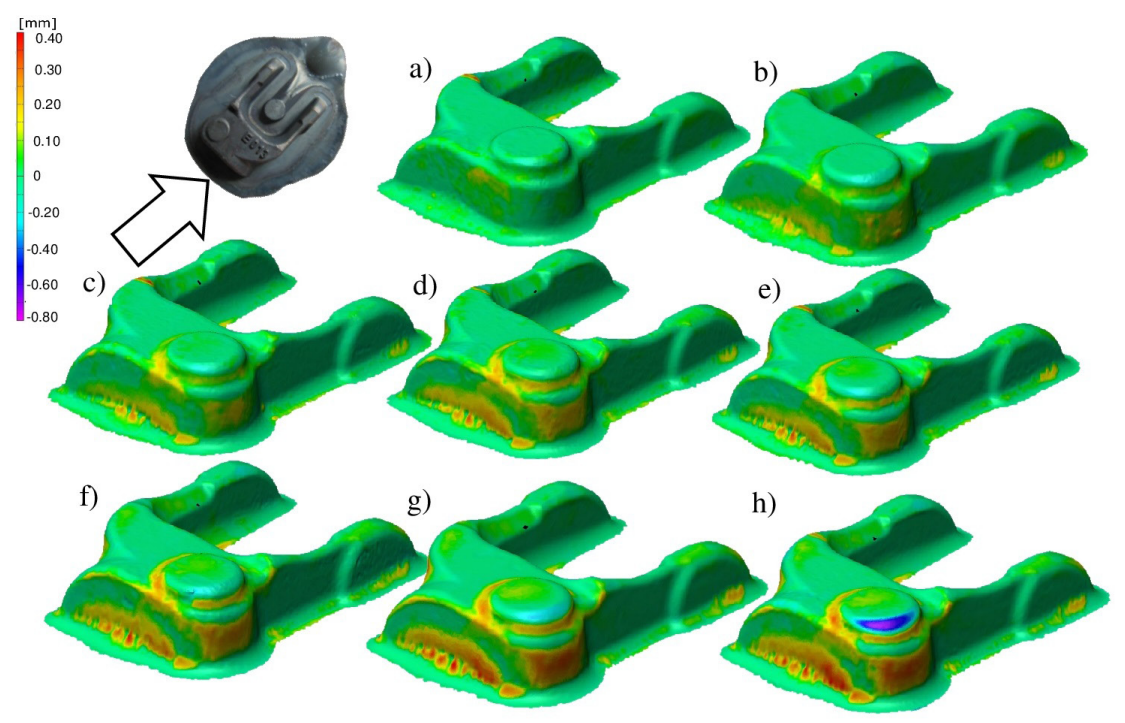

Fig.12. Comparison of selected scans of forgings manufactured using the die, in the form of shape changes of the determined surface in comparison to the 100th forging, after: a) 2000 , b) 4000 , c) 6000 , d) 8000 ,

e) 10000, f) 12000, g) 14000 , h) 16000 , forgings

Considering the very low values of insert wear (Fig. 9d), for the forging with asymmetrical shape selected for analysis, it was decided to first analyze the possibilities of determining volume changes on the selected tool surface (Fig. 9d) on which the greatest material wear (geometric loss) was observed. In order to determine a chart de- scribing the dependency of volumetric wear on the number of manufactured forgings during the forging process, it is necessary to calculate volume changes in scans of successive forgings compared to the scan of the 100th nominal forgings, which were equalized using a reference surface as shown in Fig. 12. An algorithm making it pos- 
sible to determine the volume in specific areas is used during analysis by means of POLYWORKS software. The selected software makes it possible to fill the volume between two previously equalized scans (scan of the nominal 100th forging to the scan of the nth forging) by means of tetragonal prisms with the set base length standing next to one another (Fig. 13c and 13d).

As a result of this operation, green groups of prisms appear, indicating that volume increased in this area of the forging (positive volume), while red prism groups (negative volume) indicate a loss of volume (Fig. 13c and 13d). Of course, the situation is reversed in the case of the tool. In this case, the size of a single prism base is significant. The software makes it possible to apply a triangle with a side of $0.01 \mathrm{~mm}$ as the smallest (Fig. 13d).

The assumption adopted in this manner made it possible to calculate volumes (Fig. 13d) which, when subtracted from one another, made it possible to determine the wear values (volume changes) sought in the considered area of the forging. Fig. 13e presents a chart describing the dependency of volumetric wear on the number of forgings manufacturing over the course of the forging process. It should be noted that a green color signifies sought values of volume increases. This value is calculated relative to the nominal 100th forging in the considered area for the $\mathrm{n}$-th forging and simultaneously constitutes the size of the volume change - loss of tool material. Analogously, a red color signifies groups of prisms indicating loss of volume, which may be related to material underfill or an error arising from improper matching of scans due to e.g. scanning of improperly cleaned forgings covered with scale. The layer of scale periodically adheres to tools, causing changes in the geometry of forgings, and falls of later, making this error impossible to eliminate. As can be seen on the chart in Fig. 13e, the red curve is at a significantly lower level (error of measurement, underfill, scale adhesion traces) relative to the progression of the green curve (die insert wear). Because of this, values of the green curve were accepted during analysis of tool wear

The next stage was analogous analysis of volume changes conducted for the purpose of determining the wear history of the entire surface of the bottom die insert on the basis of scanning of forgings periodically collected from the process (Fig. 14a). It should be clearly emphasized that measurement of volume changes in the final manufactured forging is verified against measurement of the tool's volume at the end of work.
Analysis of this chart makes it possible to state consistency of measurement results pertaining to the forging and die insert (material accretion on forging $220 \mathrm{~mm}^{3}$, loss on insert $236 \mathrm{~mm}^{3}$ ). Based on the shape of the curve, a visible trend in the form of a stable wear process up to approx. 5000 forgings can be observed. However, above 5500 forgings, it can be seen that the wear process accelerated while maintaining a linear character. A similar situation was observed for other forging processes, where comprehensive macro- and micro-structural investigations confirmed a slow wear process up to approx. 3000-4500 forgings, since tools in these processes are often coated with protective layers (nitriding, coatings, other), which protect tools against thermomechanical fatigue. As the number of forgings grows, greater particles of tool are detached, intensifying abrasive wear. As demonstrated by previous analyses of die insert scans after different variants, ensuring better tribological conditions, e.g. through the application of an optimized lubrication system, can limit this tool degradation process significantly.

\section{CONCLUSION}

This article concerns the possibility of applying contactless reverse scanning techniques for rapid and reliable wear analysis of die inserts of complicated shape by means of an RS3 scanner integrated with a ROMER Absolute ARM 7520si measuring arm. The presented test results show that the proposed new approach to analysis of tool wear by means of reverse 3D scanning can be used in real-life applications (including for tools with complicated geometry). Until now, this method was successfully applied to axially symmetrical objects with relatively simple shapes and high values of material loss. However in the case of a forked forging, such analysis is a significantly more difficult task.

The first part of the paper presents results of studies concerning comparative analysis via scanning of die inserts after different variants (after different numbers of forgings, two different tool materials and under different tribological conditions). Based on analyses of obtained results, the best solution for improving tool lifetime is to apply Unimax steel as the tool material and the new lubricating device, which ensures better and repeatable lubrication conditions. 
a)
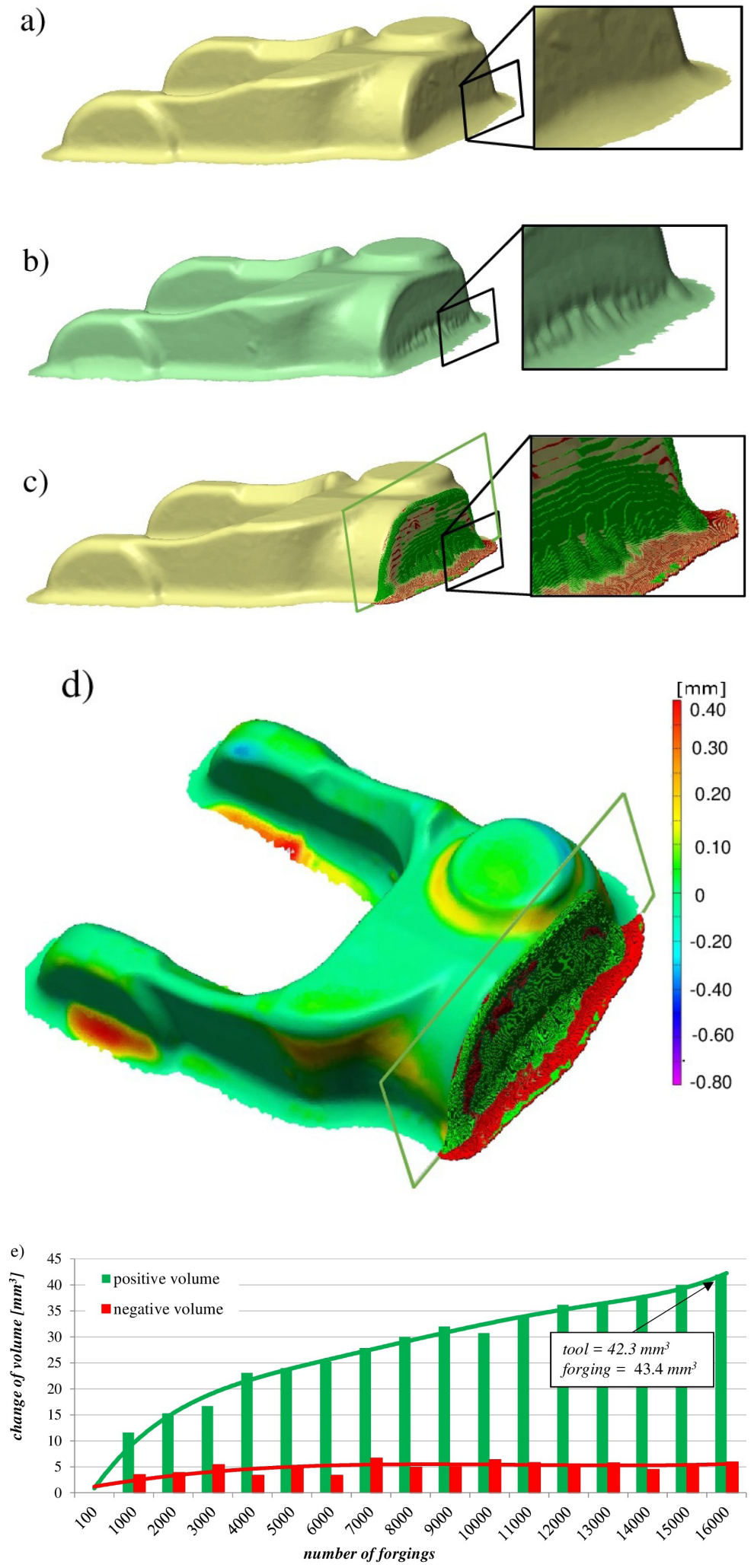

Fig.13. Example of measurements of forging volume for selected tool surface: a) scan of the nominal 100th forging, b) scan of the 16,000th forging, c) example of filling equalized forgings with prisms (base size $0.1 \mathrm{~mm}$ ) on the background of the scan of the 100th forging, d) example of filling equalized scans with prisms (base size $0.01 \mathrm{~mm}$ ) on the background of the color map of deviations, e) chart describing the dependency of volumetric wear on the number of forgings manufacturing over the course of the forging process 


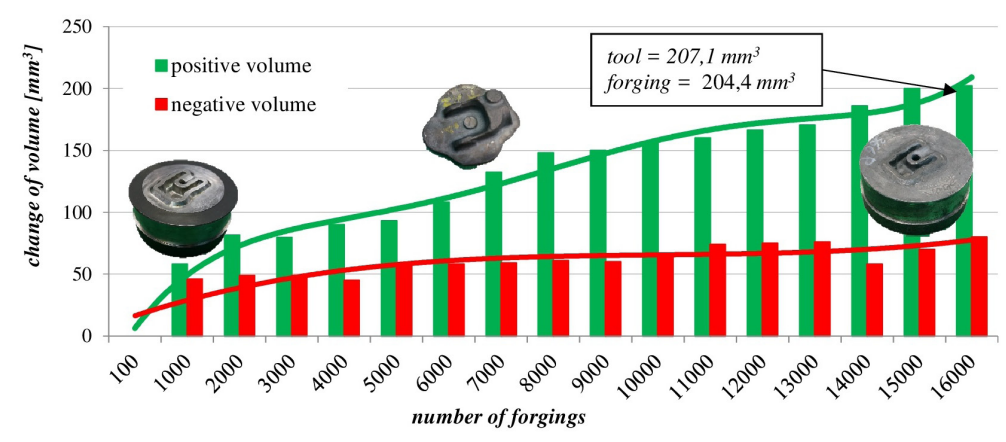

Fig. 14. Dependency describing volumetric die wear as a function of the number of forgings manufactured

In the second part of the article, the expanded reverse scanning method was employed to reconstruct the history of changes in the selected die insert based on changes in the geometry of forgings cyclically collected from the forging process. Very high consistency of forging measurement results was obtained for the die insert, both for the selected fragment of the tool and the entire working impression. Results were verified on the basis of measurement of volume changes for the 16000th forging and volume changes for the die insert after this number of manufactured forgings.

The application of the reverse scanning method allows for continuous (practical) control of forging tools' condition over the course of the process. This approach is a far more practical solution as it does not require interruption of production and dismounting of the selected tool after a specific number of forgings. It allows for detailed reconstruction of the history of tool wear progression without the need to dismount tools from the forging unit and measure them in a laboratory, which has many practical but also financially quantifiable benefits. It makes it possible to significantly reduce the time of measurement and analysis and additionally does not interrupt nor disrupt the production process. In addition, this approach makes it possible to take prophylactic measures in cases where disturbing tool changes are observed on the basis of scanned forgings. The proposed solution should have a positive influence that increases the output of the production process and significantly reduces production costs.

\section{Acknowledgements}

The research has been financed by the National Centre of Research and Development (NCBiR); project no. POIG.01.03.01-02-063/12.

\section{REFERENCES}

1. Anders P., Hogmark S., Bergström J. Simulation and evaluation of thermal fatigue cracking of hot work tool steels. International Journal of Fatigue, 10, 2004, 1095-1107.

2. Archard J.F. Contact and Rubbing of flat surfaces. Journal of Applied Physics, 24, 1953, 981-988.

3. Berti G.A., Monti M. Thermo-mechanical fatigue life assessment of hot forging die steel. Fatigue \& Fracture of Engineering Materials \& Structures, 28(11), 2005, 1025-1034.

4. Cechura M., Chval Z. Convectional versus multiple operating press. Brno, 2013, 67-70.

5. Choi Ch., Groseclose A., Altan T. Estimation of plastic deformation and abrasive wear in warm forging dies. Journal of Materials Processing Technology, 212(8), 2012, 1742-1752.

6. Chval Z. Effect of heat load to the forming machines. MM Science Journal, 2013, 418-421.

7. Gąska A., Olszewska M. Ocena odwzorowania kształtu za pomocą współrzędnościowego ramienia pomiarowego wyposażonego w głowicę optyczną. Postępy Nauki i Techniki, 7, 2011, 37-43.

8. Groche P., Brenneis M. Manufacturing and use of novel sensoric fasteners for monitoring forming processes. Measurement, 53, 2014, 136-144.

9. Gronostajski Z. Hawryluk M., Jakubik J., Kaszuba M., Misiun G., Sadowski P. Solution examples of selected issues related to die forging. Archives of Metallurgy and Materials, 60(4), 2015, 2767-2775.

10. Gronostajski Z., Hawryluk M. The main aspects of precision forging. Archives of Civil and Mechanical Engineering, 8(2), 2008, 39-57.

11. Gronostajski Z., Hawryluk M., et al. The application of the reverse $3 \mathrm{D}$ scanning method to evaluate the wear of forging tools divided on two selected areas. International Journal of Automotive Technology, 18(4), 2017, 653-662.

12. Gronostajski Z., Hawryluk M., Kaszuba M., Ziemba J. Application of a measuring arm with an in- 
tegrated laser scanner in the analysis of the shape changes of forging instrumentation during production. Eksploatacja i Niezawodnosc - Maintenance and Reliability, 18 (2), 201,. 194-200. http:// dx.doi.org/10.17531/ein.2016.2.6.

13. Gronostajski Z., Kaszuba M., Hawryluk M., Marciniak M., Zwierzchowski M., Mazurkiewicz A., Smolik J. Improving durability of hot forging tools by applying hybrid layers. Metallurgy, 54 (4), 2015, 687-690.

14. Gronostajski Z., Kaszuba M., Polak S., Zwierzchowski M., Niechajowicz A., Hawryluk M. The failure mechanisms of hot forging dies. Materials Science and Engineering. A, Structural Materials: Properties, Microstructure and Processing, 657, 2016, 147-160.

15. Hawryluk M. Metody analizy oraz zwiększania trwałości narzędzi kuźniczych stosowanych w procesach kucia matrycowego na gorąco. Monograficzna seria wydawnicza Problemy Eksploatacji i Budowy Maszyn, ISBN 978-83-7789-410-1, Wyd. Naukowe ITE - PIB, Radom 2016.

16. Hawryluk M. Review of selected methods of increasing the life of forging tools in hot die forging processes. Archives of Civil and Mechanical Engineering, 16, 2016, 845-866. http:// dx.DOI:0.1016/j.acme.2016.06.001.

17. Hawryluk M., Mrzygłód B. A durability analysis of forging tools for different operating conditions with application of a decision support system based on artificial neural networks (ANN). Eksploatacja i Niezawodność - Maintenance and Reliability, 19(3), 2017, 338-348, http://www.ein.org.pl/sites/ default/files/2017-03-04p.pdf

18. Hawryluk M., Ziemba J. Possibilities of application measurement techniques in hot die forging processes. Measurement, 110, 2017, 284-295.

19. Hawryluk M., Ziemba J. The possibility of using scanning techniques in forging applications. Obróbka Plastyczna Metali, 27 (1), 2017, 39-58.

20. Hawryluk M., Ziemba J., Sadowski P. A review of current and new measurement techniques used in hot die forging processes. Measurement and Control, 50 (3), 2017, 74-86, https://doi. org/10.1177/0020294017707161.

21. Juras B., Szewczyk D. Dokładność pomiarów realizowanych skanerem optycznym. Postępy Nauki i Techniki, 2011, 29 $\div 36$.

22. Kima D.H., Leeb H.C., Kimc B.M., Kimd K.H. Estimation of die service life against plastic deformation and wear during hot forging processes. Journal of Materials Processing Technology, 212, 2012, 1742- 1752 .

23. Kocańda A. Określenie trwałości narzędzia w obróbce plastycznej metali, rozdział w monografii pt.
Informatyka w Technologii Metali, red. A. Piela, F. Grosman, J. Kusiak i M. Pietrzyk, Wydawnictwo Politechniki Śląskiej, Gliwice, 2003, 213-256.

24. Kuş A. Implementation of $3 \mathrm{~d}$ optical scanning technology for automotive applications. Sensors, 9, 2009, 1967-1979.

25. Lange K., Cser L., Geiger M., Kals J.A.G. Tool Life and Tool Quality in Bulk Metal Forming. Proceedings of the Institution of Mechanical Engineers, Part B: Journal of Engineering Manufacture November, 207, 1993, 223-239.

26. Lavtar L., Muhic T., Kugler G., Tercelj M. Analysis of the main types of damage on a pair of industrial dies for hot forging car steering mechanisms. Engineering Failure Analysis, 18(10), 2011, 1143-1152.

27. Lee S.R., Lee Y.K., Park C.H., Yang D.Y. A new method of preform design in hot forging by using electric field theory. Int. J. Mech. Sci, 44, 2002, 773-792.

28. Lu B., Ou H., Long H. Die shape optimisation for net-shape accuracy in metal forming using direct search and localised response surface methods. Structural and Multidisciplinary Optimization, 44, 2011, 529-545.

29. Machácek P., Tomícek J. Application of laser scanning in reverse engineering and prototype manufacturing. WTP, 1(21) 2010, 35-44.

30. Persson A., Hogmarkb S., Bergstroma J. Thermal fatigue cracking of surface engineered hot work tool steels. Surface \& Coatings Technology,191, 2005, 216-227.

31. Ratajczyk E. Współrzędnościowe ramiona pomiarowe i ich testy dokładności. Przegląd Elektrotechniczny, 5, 2008, 181-185.

32. Sedighi M., Tokmechi S. A new approach to preform design in forging process of complex parts. J. Mater. Process. Technol. 97(1-3), 2005, 314-324.

33. Starlinga C., Brancob J. Thermal fatigue of hot work tool steel with hard coatings. Thin Solid Films, 308(309), 1997, 436-442.

34. Taylan A., Gracious N., Gangshu S. Cold and hot forging fundamentals and application. ASM International. Asm metals handbook, 14, 2005, 337-338.

35. Vazquez V., Altan T. Die design for flashless forging of complex parts. J. Mater. Process. Technol, 98, 2000, 81-89.

36. Wieczorowski M., Ruciński M., Koteras R. Application of optical scanning for measurements of castings and cores. Archives of Foundry Engineering, 10, 2010, 265-268.

37. Xian-bin Fu., Bin Liu., Yu-cun Z., Li-na L. Fault diagnosis of hydraulic system in large forging hydraulic press. Measurement, 49, 2014, 390-396. 